\title{
AVALIAÇÃo dA ARBORIZAÇÃo dE VIAS PÚBLICAS DE UMA ÁREA DA REGIÃO OESTE DA CIDADE DE FRANCA/SP
}

\author{
Mateus Domingos Mendes Silva ${ }^{1}$, Renato de Paula Silveira², Maria Inês Junqueira Garcia \\ Teixeira $^{3}$
}

(recebido em 11.10.2007 e aceito pra publicação em 06.03.2008)

\begin{abstract}
RESUMO
O presente estudo teve por objetivo realizar uma análise qualitativa e quantitativa da arborização das vias públicas dos bairros Vila Raycos, Jardim Independência, Jardim Califórnia e da parte antiga da Vila Santos Dumont da cidade de Franca, SP. Foram encontrados 479 indivíduos de 72 espécies, pertencentes a 33 famílias. A distribuição pelas vias públicas foi bastante irregular, decorrente de plantios aleatórios realizados pelos próprios moradores sem a observância de critérios essenciais para a escolha de espécies mais adequadas ao local. Isto ocasionou um alto índice de podas (71\%) para evitar conflitos, que se mostraram em menor número em decorrência desta prática. Quanto à origem, 68,5\% de indivíduos eram exóticos e 31,5\% eram nativos do Brasil. Destes, apenas 8,3\% eram nativos da região. Faz-se necessário um maior empenho dos órgãos públicos e da população para implementar um plano de arborização na área.
\end{abstract}

Palavras-chave: arborização urbana; árvores urbanas; florística urbana; Franca.

\footnotetext{
${ }^{1}$ Biólogo, Especialista em Ciência Ambiental, Franca, São Paulo, mateusinho@netsite.com.br

${ }^{2}$ Biólogo, Franca, São Paulo, renatopsilveira@yahoo.com.br

${ }^{3}$ Bióloga, Mestre em Produção Vegetal, Universidade de Franca, Curso de Ciências Biológicas,

Franca, São Paulo, mariainesjgt@hotmail.com
} 


\title{
VALUATION OF THE ARBORIZATION OF PUBLIC SIDEWALKS OF THE WEST AREA IN THE CITY OF FRANCA/SP
}

\begin{abstract}
The present study had the main objective to carry out a qualitative and quantitative analysis of the process of arborization of some public ways in these specific districts: Vila Raycos, Jardim Independência, Jardim Califórnia and the oldest part of Vila Santos Dumont. They all lie in Franca, State of São Paulo. It was found 479 individuals of 72 species belonging to 33 families. The distribution of these species was quite irregular due to the random way of planting. The inhabitants of these districts did not observe the essential criteria for choose the most appropriate species for the place. It was responsible for a high index of prunings $(71 \%)$, this happened to avoid disagreement that had shown in a lesser number in result of this practice. About the origin, $68,5 \%$ of the individuals were exotic and $31,5 \%$ were from Brazil. Of these, only $8,3 \%$ were native from the region. It makes necessary the interest of the public organs and the population in order to establish an arborization plan for the area.
\end{abstract}

Key words: urban arborization; urban trees; urban floristic; Franca. 


\section{INTRODUÇÃO}

Após o advento da Revolução Industrial, ou seja, a partir do século XVIII, o surgimento das fábricas impulsionou o processo de urbanização, pois gerava empregos e atraía a população rural. Nos países de industrialização antiga ou desenvolvidos, a urbanização foi geralmente mais lenta e gradual e as cidades foram estruturando-se para oferecer melhores condições de vida aos seus habitantes. Entretanto, nos países subdesenvolvidos esse processo ocorreu rápida e desordenadamente, deixando falhas no planejamento e na infra-estrutura (MOREIRA; SENE, 2002).

Contudo, os problemas sócio-ambientais urbanos são comuns a todos os países, como a grande produção de lixo que os aglomerados urbanos geram, causando poluição do solo e da água, a liberação de esgoto nos cursos d'água, a poluição atmosférica, tendo como conseqüência a inversão térmica, chuva ácida, ilhas de calor e efeito estufa, a poluição sonora e visual, a impermeabilização do solo, gerando grandes enchentes e desmoronamentos, dentre outros (ALMEIDA; RIGOLIN, 2002; MOREIRA; SENE, 2002; SILVA, 2005).

No Brasil, segundo o censo 2000 realizado pelo IBGE, 81,2\% da população vivem nas cidades. Esse alto índice demográfico em área urbana agrava ainda mais essa problemática (SILVA, 2005).

Em vista destes problemas, as áreas verdes das cidades atuam como redutoras de grande parte dos impactos ambientais. Dentre os inúmeros benefícios que a presença da vegetação no meio urbano traz, destacam-se a diminuição da poluição sonora, visual e atmosférica, com a purificação do ar, absorção de dióxido de carbono e retenção de partículas sólidas em suspensão; proteção contra ventos e chuva; absorção de parte dos raios solares, proporcionando sombreamento; aumento das áreas de infiltração; proteção do solo contra erosões; manutenção do equilíbrio microclimático por meio da diminuição da amplitude térmica e aumento da umidade relativa do ar em conseqüência da evapotranspiração; valorização estética e paisagística do local e atração da fauna da região.

Todos esses fatores somados proporcionam o bem estar da população, influindo na melhoria de sua saúde física e mental (SOARES, 1998; TEIXEIRA, 1999; MILANO; DALCIN, 2000; CEMIG, 2001; SANTOS, 2001; ROCHA; LELES; OLIVEIRA NETO, 2004).

Todavia, grande parte dos municípios enfrenta uma série de problemas e muitas vezes a maioria das prefeituras não se preocupam com o planejamento da arborização, o que leva os próprios moradores a realizar o plantio nas vias públicas. Desse modo, o padrão observado em muitas cidades brasileiras é de uma arborização irregular, inadequada e descontínua. 
Este trabalho objetivou analisar a situação da arborização de uma área na cidade de Franca, estado de São Paulo, na qual não houve planejamento da arborização urbana.

\section{MATERIAL E MÉTODOS}

O município de Franca está localizado na região nordeste do Estado de São Paulo,

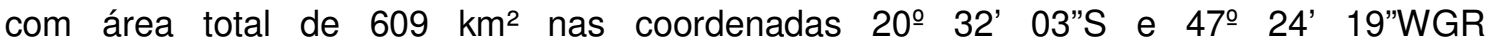
(PREFEITURA..., 2006).

O planalto francano é bastante elevado, com altitude de 1.040 metros. A precipitação média anual histórica registrada pelo Departamento de Águas e Energia Elétrica/Centro Tecnológico de Hidráulica é de 1.644,30 mm (COMITÊ..., 2005), predominando um clima tropical de altitude, com inverno seco e temperatura média anual de $19 \stackrel{\circ}{\circ} \mathrm{C}$. A vegetação dominante é o Cerrado, encontrado principalmente nas áreas mais elevadas com solos mais pobres derivados da decomposição dos arenitos (VIEIRA, 1971). As florestas se restringem às encostas e partes baixas (MARQUETI, 1992).

Segundo o Censo 2000 realizado pelo IBGE, a população do município era de 287.400 habitantes, com população estimada para 2005 de 321.969 (IBGE, 2006). A área urbana possui $84 \mathrm{Km}^{2}$, contando com 236 bairros (Figura 1).

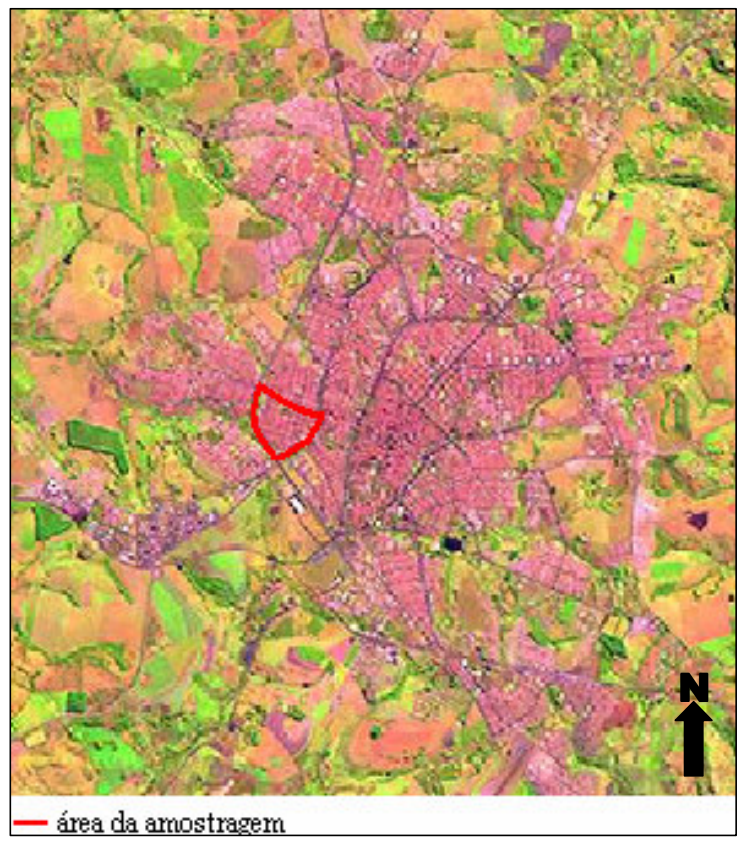

Figura 1 - Imagem de satélite da área urbana da cidade de Franca/SP (EMBRAPA, 2006). 
Compreendendo $845.470 \mathrm{~m}^{2}$, a área estudada engloba quatro bairros predominantemente residenciais da região oeste da cidade: Vila Raycos, Jardim Independência, Jardim Califórnia e a parte antiga da Vila Santos Dumont, dos quais foram percorridas 28 vias públicas. Esses bairros são antigos, com cerca de 50 anos, de acordo com o setor de Cadastro Físico da Prefeitura Municipal, quando não havia um planejamento de arborização urbana. Em conseqüência, a área foi arborizada pelos próprios moradores, sem orientação e observação de alguns critérios essenciais.

Como delimitadoras da área, foram consideradas a rua Francisco Marques, a avenida Santos Dumont e a rodovia Cândido Portinari (SP 334) (Figura 2), observando-se que entre a rodovia e os bairros há uma área de voçoroca e alguns terrenos escarpados.

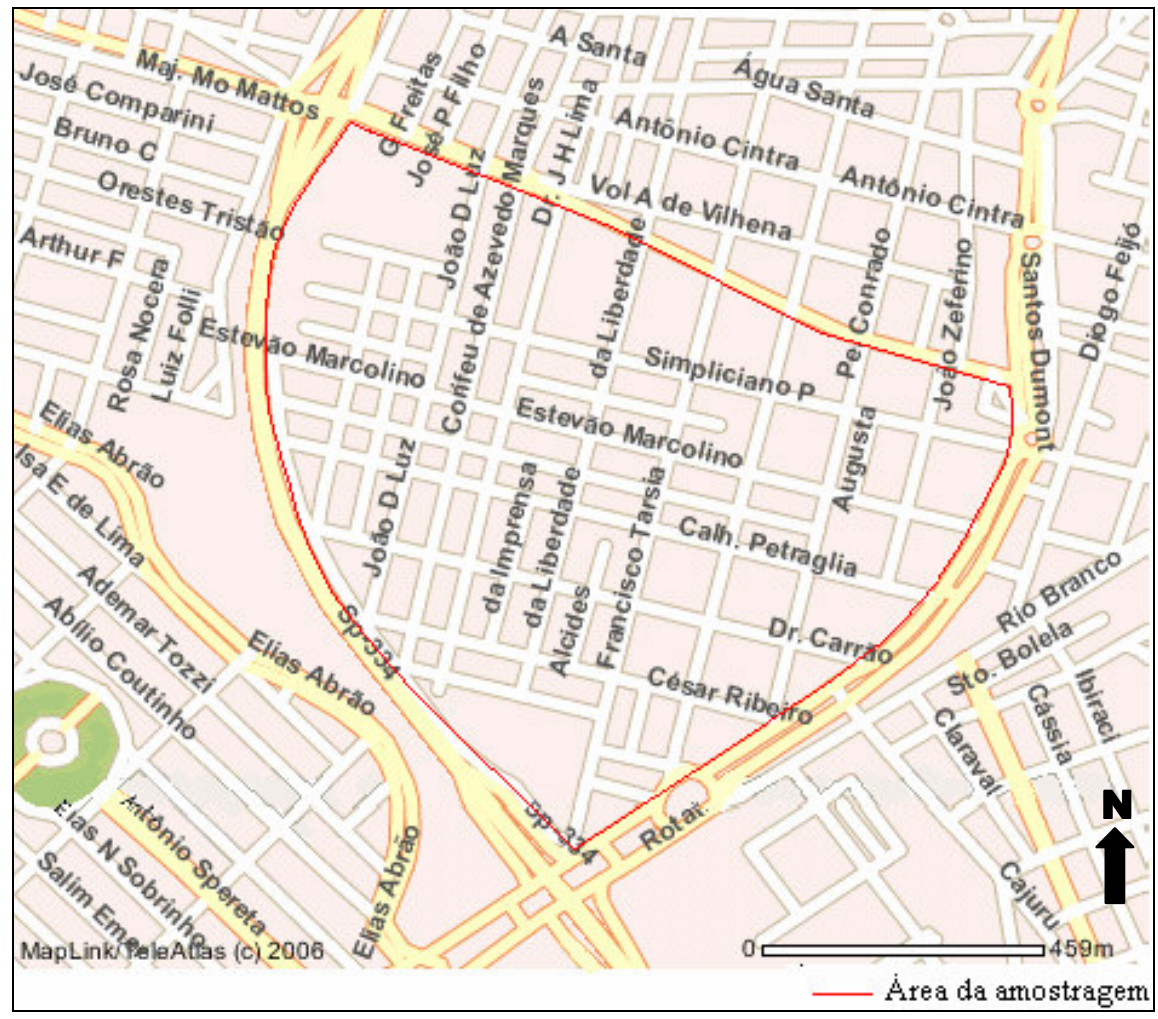

Figura 2 - Mapa da área de amostragem, na região oeste da cidade de Franca/SP (TELELISTAS.NET, 2006).

A coleta dos dados foi realizada em março de 2006, considerando-se todos os indivíduos plantados nas calçadas, abrangendo espécies arbóreas de pequeno (altura de 4$6 \mathrm{~m}$, com copa inferior a $4 \mathrm{~m}$ ), médio (altura de 6-10m, com copa de 4-6m) e grande porte (com altura acima de 10m e copa com dimensões acima de $6 \mathrm{~m}$ ), assim como espécies arbustivas (altura de 3-6m, ramificados desde sua base) e indivíduos recém plantados (MASCARÓ; MASCARÓ, 2005). Foram excluídos aqueles indivíduos que se encontravam 
dentro dos jardins residenciais, indivíduos mortos, bem como as árvores plantadas em praças públicas e canteiros centrais.

Para a coleta foi efetuada uma amostragem de caracteres qualitativo e quantitativo e os seguintes itens foram observados e anotados:

1- rua: nome da rua, de acordo com o mapa oficial do município;

2- número: número da residência na qual o indivíduo se encontra;

3- espécie: nome popular da espécie;

4- C.A.C.: circunferência à altura do colo, dada em centímetros;

5- altura: altura estimada em metros;

6- rede elétrica:

a) presença ou ausência,

b) conflito (sim/não).

7- impedimento à visualização da sinalização de trânsito (sim/não);

8- danos à calçada (sim/não);

9- obstrução da passagem de pedestres (sim/não);

10- poda efetuada:

a) ausente, inclusive para os indivíduos que não podem ser podados (palmeiras),

b) moderada: aquela que não compromete a estrutura da planta,

c) drástica: aquela que compromete a estrutura e o desenvolvimento da planta.

Utilizou-se circunferência à altura do colo (C.A.C.), e não à altura do peito (C.A.P.), pois muitos indivíduos encontravam-se bastante ramificados a uma altura de 1,30m, como arbustos, por exemplo. Para a estimativa da altura, estendia-se uma trena de dois metros ao longo do caule do indivíduo, pela qual, a certa distância, uma outra pessoa comparava a proporção de uma régua em relação à trena. Conforme a quantidade de centímetros marcados na régua, correspondente aos dois metros, estimava-se altura total.

\section{RESULTADOS E DISCUSSÃO}

$\mathrm{Na}$ área estudada foram encontradas 72 espécies distribuídas em 33 famílias (Tabela 1), num total de 479 indivíduos. 
Tabela 1 - Composição florística dos indivíduos encontrados nas vias públicas dos bairros Vila Raycos, Jardim Independência, Jardim Califórnia e na parte antiga da Vila Santos Dumont da cidade de Franca, SP.

\begin{tabular}{|c|c|c|}
\hline FAMÍLIA/ESPÉCIE & NOME POPULAR & ORIGEM \\
\hline \multicolumn{3}{|l|}{ ALLIACEAE } \\
\hline $\begin{array}{l}\text { Dracaena fragans } \\
\text { ANACARDIACEAE }\end{array}$ & dracena & $E$ \\
\hline Mangifera indica & mangueira & $E$ \\
\hline Schinus molle & chinus & $\mathrm{N}$ \\
\hline $\begin{array}{l}\text { Schinus terebinthifolius } \\
\text { ANNONACEAE }\end{array}$ & aroeira-da-praia & NR \\
\hline Annona muricata & graviola & $\mathrm{E}$ \\
\hline Rollinia mucosa & fruta-do-conde & $\mathrm{N}$ \\
\hline \multicolumn{3}{|l|}{ APOCYNACEAE } \\
\hline Nerium oleander & espirradeira & $E$ \\
\hline ARALIACEAE & & \\
\hline Schefflera arboricola & cheflera & $E$ \\
\hline \multicolumn{3}{|l|}{ ARECACEAE } \\
\hline Archontophoenix sp & palmeira seafórtia & $\mathrm{E}$ \\
\hline Caryota mitis & palmeira cariota & $E$ \\
\hline Dypsis lutescens & areca bambu & $E$ \\
\hline Syagrus romanzoffiana & jerivá & NR \\
\hline \multicolumn{3}{|l|}{ BIGNONIACEAE } \\
\hline Spathodea nilotica & espatódea & $E$ \\
\hline Tabebuia chrysotricha & ipê amarelo & NR \\
\hline Tabebuia impetiginosa & ipê roxo & NR \\
\hline Tabebuia roseo-alba & ipê & $\mathrm{N}$ \\
\hline Tabebuia umbellata & ipê amarelo branco & $\mathrm{N}$ \\
\hline Tecoma stans & ipê-de-jardim & $E$ \\
\hline \multicolumn{3}{|l|}{ BIXACEAE } \\
\hline $\begin{array}{l}\text { Bixa orelana } \\
\text { CARICACEAE }\end{array}$ & urucum & NR \\
\hline Carica papaya & mamão & $E$ \\
\hline \multicolumn{3}{|l|}{ CHRYSOBALANACEAE } \\
\hline Licania tomentosa & oiti & $\mathrm{N}$ \\
\hline \multicolumn{3}{|l|}{ COMBRETACEAE } \\
\hline Terminalia catappa & sete-copas & $E$ \\
\hline \multicolumn{3}{|l|}{ CUPRESSACEAE } \\
\hline Thuja sp & cipreste & $E$ \\
\hline \multicolumn{3}{|l|}{ EUPHORBIACEAE } \\
\hline Codiaeum variegatum & cróton & $E$ \\
\hline Euphorbia pulcherrima & bico-de-papagaio & $\mathrm{E}$ \\
\hline Jatropha sp & jatrofa & $\mathrm{E}$ \\
\hline $\begin{array}{l}\text { FABACEAE - Caesalpinioideae } \\
\text { Bauhinia variegata }\end{array}$ & unha-de-boi rosa & $\mathrm{E}$ \\
\hline Bauhinia variegata var candida & unha-de-boi branca & $\mathrm{E}$ \\
\hline Caesalpinia pluviosa & sibipiruna & $\bar{N}$ \\
\hline Caesalpinia pulcherrima & flamboiant-mirim vermelho & $E$ \\
\hline Caesalpinia pulcherrima var flava & flamboiant-mirim amarelo & $E$ \\
\hline Cassia fistula & chuva-de-ouro & $\mathrm{E}$ \\
\hline Cassia leptophylla & cássia & $\mathrm{N}$ \\
\hline Schizolobium parahyba & guapuruvu & NR \\
\hline
\end{tabular}




\begin{tabular}{|c|c|c|}
\hline FAMÍLIA/ESPÉCIE & NOME POPULAR & ORIGEM \\
\hline $\begin{array}{l}\text { Tamarindus indica } \\
\text { FABACEAE - Mimosoideae }\end{array}$ & tamarindo & $E$ \\
\hline Adenanthera pavonina & cássia carolina & $E$ \\
\hline $\begin{array}{l}\text { Anadenanthera macrocarpa } \\
\text { FABACEAE - Papilionoideae }\end{array}$ & angico vermelho & NR \\
\hline Cajanus cajan & feijão nandu & $E$ \\
\hline Gliricidia sepium & gliricídia & $\bar{E}$ \\
\hline Holocalyx balansae & alecrim-de-campinas & NR \\
\hline Myroxylon peruiferum & bálsamo & NR \\
\hline \multicolumn{3}{|l|}{ LAURACEAE } \\
\hline Nectandra megapotamica & canelinha & NR \\
\hline Persea americana & abacateiro & $E$ \\
\hline \multicolumn{3}{|l|}{ MAGNOLIACEAE } \\
\hline Michelia champaca & magnólia-amarela & $E$ \\
\hline \multicolumn{3}{|l|}{ MALPIGHIACEAE } \\
\hline $\begin{array}{l}\text { Malpighia glabra } \\
\text { MALVACEAE }\end{array}$ & acerola & $E$ \\
\hline Bombacopsis glabra & castanha-do-maranhão & $E$ \\
\hline Ceiba speciosa & paineira & $\mathrm{N}$ \\
\hline Hibiscus rosa-sinensis & hibisco & NR \\
\hline Pachira aquatica & munguba & $\mathrm{N}$ \\
\hline \multicolumn{3}{|l|}{ MELASTOMATACEAE } \\
\hline Tibouchina granulosa & quaresmeira & NR \\
\hline Tibouchina mutabilis & manacá-da-serra & $\mathrm{N}$ \\
\hline \multicolumn{3}{|l|}{ MORACEAE } \\
\hline Ficus benjamina & ficus & $\mathrm{E}$ \\
\hline Ficus benjamina var variegata & ficus variegado & $E$ \\
\hline Morus nigra & amora & $E$ \\
\hline \multicolumn{3}{|l|}{ MORINGACEAE } \\
\hline \multicolumn{3}{|l|}{ MYRTACEAE } \\
\hline Callistemon viminalis & escova-de-garrafa & $E$ \\
\hline Eugenia brasiliensis & grumixama & $\mathrm{N}$ \\
\hline Psidium guajava & goiabeira & NR \\
\hline Syzygium cumini & jambolão & $E$ \\
\hline \multicolumn{3}{|l|}{ NYCTAGINACEAE } \\
\hline Bougainvillea spectabilis & primavera & NR \\
\hline \multicolumn{3}{|l|}{ OLEACEAE } \\
\hline $\begin{array}{l}\text { Ligustrum lucidum } \\
\text { PROTEACEAE }\end{array}$ & ligustro & $E$ \\
\hline \multicolumn{3}{|l|}{ RUTACEAE } \\
\hline Citrus limonia & limão-china & $E$ \\
\hline Citrus limon & limão & $E$ \\
\hline Citrus reticulata & mexeriqueira & $E$ \\
\hline Citrus sinensis & laranjeira & $E$ \\
\hline Murraya paniculata & murta & $E$ \\
\hline \multicolumn{3}{|l|}{ SAPINDACEAE } \\
\hline $\begin{array}{l}\text { Sapindus saponaria } \\
\text { SOLANACEAE }\end{array}$ & sabão-de-macaco & $\mathrm{N}$ \\
\hline Brunfelsia uniflora & manacá-de-cheiro & $\mathrm{N}$ \\
\hline
\end{tabular}




\begin{tabular}{|c|c|c|}
\hline FAMÍLIA/ESPÉCIE & NOME POPULAR & ORIGEM \\
\hline Cestrum nocturnum & dama-da-noite & $E$ \\
\hline $\begin{array}{l}\text { TAXODIACEAE } \\
\text { Cryptomeria japonica var elegans }\end{array}$ & árvore-de-natal & $E$ \\
\hline $\begin{array}{l}\text { VERBENACEAE } \\
\text { Duranta repens var aurea }\end{array}$ & pingo-de-ouro & $\mathrm{N}$ \\
\hline
\end{tabular}

As cinco famílias que apresentaram maior número de indivíduos foram Rutaceae, Fabaceae-Caesalpinioideae, Anacardiaceae, Oleaceae e Moraceae, perfazendo, respectivamente, $15 \%, 11,9 \%, 10,6 \%, 10,2 \%$ e $8,9 \%$ do total da amostragem. As espécies mais freqüentes foram Murraya paniculata com 12,3\%, Ligustrum lucidum com 10,2\%, Schinus molle com 8,9\%, Ficus benjamina com 7,5\% e Terminalia catappa com 6,2\% (Tabela 2).

Das espécies mais freqüentes, as dez primeiras representam $14,1 \%$ do total de espécies, perfazendo $64,5 \%$ do total de indivíduos. O restante das espécies apresenta, em sua maioria, menos de cinco representantes cada uma, indicando uma distribuição bastante irregular, decorrente de plantios aleatórios realizados pelos próprios moradores. Ao considerar riscos de pragas e doenças, as espécies utilizadas em arborização urbana não devem ultrapassar 15\% da população total (GREY; DENEKE,1978). Na área estudada, o máximo que se encontrou de uma só espécie foi de 12,31\%, enquadrando-se no parâmetro indicado. Embora a utilização de uma só espécie para cada rua ou para um certo número de quarteirões seja indicada, alegando que assim haja um melhor efeito paisagístico (CEMIG, 2001), corre-se o risco, com tal uniformidade, de maior susceptibilidade a pragas e doenças. Porém, o plantio misto dificulta o trabalho das equipes de poda, pois cada espécie apresenta uma época mais apropriada para este manejo. 
Tabela 2 - Espécies, número de indivíduos ( $\mathrm{N}^{\circ}$ ind.) e freqüência relativa $(\mathrm{FR})$ dos indivíduos encontrados na arborização das vias públicas dos bairros Vila Raycos, Jardim Independência, Jardim Califórnia e a parte antiga da Vila Santos Dumont da cidade de Franca, SP.

\begin{tabular}{|c|c|c|c|c|c|}
\hline Espécie & $\begin{array}{l}\mathbf{N}^{\circ} \\
\text { ind. }\end{array}$ & FR (\%) & Espécie & $\begin{array}{l}\mathbf{N}^{\circ} \\
\text { ind. }\end{array}$ & FR (\%) \\
\hline Murraya paniculata & 59 & 12,31 & Sapindus saponaria & 3 & 0,62 \\
\hline Ligustrum lucidum & 49 & 10,22 & Adenanthera pavonina & 2 & 0,41 \\
\hline Schinus molle & 43 & 8,97 & Caesalpinia pulcherrima var flava & 2 & 0,41 \\
\hline Ficus benjamina & 36 & 7,51 & Carica papaya & 2 & 0,41 \\
\hline Terminalia catappa & 30 & 6,2 & Caryota mitis & 2 & 0,41 \\
\hline Caesalpinia pluviosa & 23 & 4,8 & Cassia leptophylla & 2 & 0,41 \\
\hline Michelia champaca & 21 & 4,38 & Cestrum nocturnum & 2 & 0,41 \\
\hline Licania tomentosa & 20 & 4,17 & Ceiba speciosa & 2 & 0,41 \\
\hline Bauhinia variegata var candida & 14 & 2,92 & Cryptomeria japonica var elegans & 2 & 0,41 \\
\hline Spathodea nilotica & 14 & 2,92 & Nectandra megapotamica & 2 & 0,41 \\
\hline Tecoma stans & 9 & 1,87 & Pachira aquatica & 2 & 0,41 \\
\hline Tabebuia chrysotricha & 8 & 1,67 & Rollinia mucosa & 2 & 0,41 \\
\hline Syzygium cumini & 7 & 1,46 & Schefflera arboricola & 2 & 0,41 \\
\hline Caesalpinia pulcherrima & 6 & 1,25 & Syagrus romanzoffiana & 2 & 0,41 \\
\hline Duranta repens var aurea & 6 & 1,25 & Tabebuia roseo-alba & 2 & 0,41 \\
\hline Tibouchina granulosa & 6 & 1,25 & Tibouchina mutabilis & 2 & 0,41 \\
\hline Bauhinia variegata & 5 & 1,04 & Anadenanthera macrocarpa & 1 & 0,21 \\
\hline Malpighia glabra & 5 & 1,04 & Annona muricata & 1 & 0,21 \\
\hline Schinus terebinthifolius & 5 & 1,04 & Archontophoenix sp & 1 & 0,21 \\
\hline Brunfelsia uniflora & 4 & 0,83 & Bixa orelana & 1 & 0,21 \\
\hline Callistemon viminalis & 4 & 0,83 & Bombacopsis glabra & 1 & 0,21 \\
\hline Citrus sinensis & 4 & 0,83 & Bougainvillea spectabilis & 1 & 0,21 \\
\hline Euphorbia pulcherrima & 4 & 0,83 & Codiaeum variegatum & 1 & 0,21 \\
\hline Ficus benjamina var variegata & 4 & 0,83 & Dracaena fragans & 1 & 0,21 \\
\hline Hibiscus rosa-sinensis & 4 & 0,83 & Eugenia brasiliensis & 1 & 0,21 \\
\hline Myroxylon peruiferum & 4 & 0,83 & Gliricidia sepium & 1 & 0,21 \\
\hline Persea americana & 4 & 0,83 & Grevillea banksii & 1 & 0,21 \\
\hline Psidium guajava & 4 & 0,83 & Holocalyx balansae & 1 & 0,21 \\
\hline Cajanus cajan & 3 & 0,62 & Jatropha sp & 1 & 0,21 \\
\hline Cassia fistula & 3 & 0,62 & Moringa oleifera & 1 & 0,21 \\
\hline Citrus limon & 3 & 0,62 & Nerium oleander & 1 & 0,21 \\
\hline Citrus limonia & 3 & 0,62 & Schizolobium parahyba & 1 & 0,21 \\
\hline Citrus reticulata & 3 & 0,62 & Tabebuia impetiginosa & 1 & 0,21 \\
\hline Dypsis lutescens & 3 & 0,62 & Tabebuia umbellata & 1 & 0,21 \\
\hline Mangifera indica & 3 & 0,62 & Tamarindus indica & 1 & 0,21 \\
\hline Morus nigra & 3 & 0,62 & Thuja sp & 1 & 0,21 \\
\hline
\end{tabular}

Quanto à origem, foram encontrados $68,5 \%$ de indivíduos exóticos e $31,5 \%$ de indivíduos nativos do Brasil. Segundo o Código do Meio Ambiente de Franca, art. 49, §1 "a espécie arbórea a ser plantada deve ser escolhida dentro das espécies mais representativas da flora regional" (FRANCA, 1996). Das espécies nativas, 53,6\% são nativas da região (Tabela 1), sendo que estas perfazem apenas $8,3 \%$ do total de indivíduos. Isso demonstra, em parte, falta de interesse dos órgãos públicos em oferecer mudas da flora regional e em incentivar o plantio das mesmas, pois a Prefeitura Municipal é a responsável pela autorização do plantio de árvores nas calçadas, conforme preconiza o Código do Meio Ambiente do Município de Franca, art. 49 § 2:. "os moradores nas propriedades adjacentes aos passeios públicos poderão neles plantar árvores, desde que autorizados pela Prefeitura" (FRANCA, 1996). A utilização de espécies de árvores nativas é insignificante considerando- 
se a riqueza de nossa flora, principalmente pelo desconhecimento da mesma (LORENZI, 2002).

O Código diz, também, que estas espécies devem oferecer alimento à fauna (FRANCA, 1996). Cerca de $65 \%$ do total de indivíduos encontrados produzem frutos que são potencialmente utilizados como alimento, principalmente por aves e morcegos. A utilização de espécies exóticas desde o início de nossa colonização foi a grande responsável pelo desaparecimento de grande parte dos animais dos centros urbanos devido a não adaptação aos novos tipos de alimento (LORENZI, 2002).

A maior parte das árvores $(65,3 \%)$ possuía circunferência à altura do colo superior a $51 \mathrm{~cm}$, caracterizando indivíduos adultos (Figura 3).

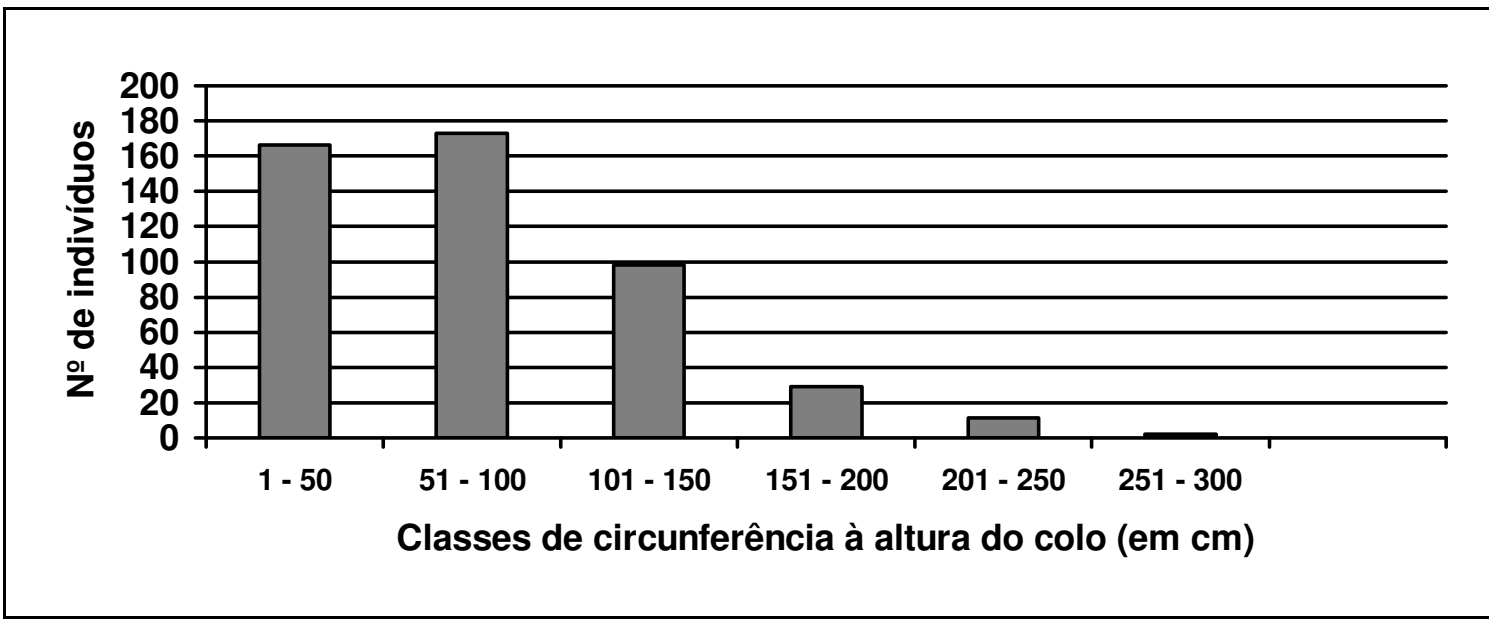

Figura 3 - Classes de circunferência à altura do colo dos indivíduos encontrados na arborização das vias públicas dos bairros Vila Raycos, Jardim Independência, Jardim Califórnia e na parte antiga da Vila Santos Dumont da cidade de Franca, SP.

Ao observar a condição das calçadas, verificou-se que $34,2 \%$ dos indivíduos as danificavam. Nas árvores adultas, na maioria das vezes a área de infiltração era insuficiente para permitir adubações, aeração do solo e entrada de água da chuva, sendo inferiores a $1 \mathrm{~m}^{2}$, como recomendado (CEMIG, 2001).

Foram encontrados $45,3 \%$ dos indivíduos debaixo da fiação, enquanto $54,7 \%$ não estavam sob a fiação. Dos indivíduos sob a fiação que não estão em conflito com os fios (191), 38,2\% sofreram algum tipo de poda, e 61,8\% ainda não atingiram a altura da fiação.

De um modo geral, 76,8\% dos indivíduos apresentaram altura estimada inferior ou igual a 6 m. Porém, nos indivíduos sob a fiação (217), este valor foi de $87 \%$, indicando que conflitavam, possivelmente, apenas com os cabos aéreos de telefone, pois os cabos de energia elétrica encontram-se a partir dos $6 \mathrm{~m}$. Dos indivíduos que estavam sob a fiação foram encontrados 13\% acima dos $6 \mathrm{~m}$ e 12\% conflitavam com a mesma (Figura 4). Para 
evitar o conflito com a fiação, sugere-se a utilização de espécies de pequeno porte, não alcançando a fiação, ou de grande porte, que ultrapassem a fiação, desde que para estas haja largura suficiente das calçadas e afastamento das construções (MILANO; DALCIN, 2000). Nas espécies de médio porte geralmente há coincidência com a altura dos fios e a copa das árvores. Outra vantagem apresentada pelas espécies de grande porte ao ultrapassarem os fios, é que a iluminação pública não é prejudicada.

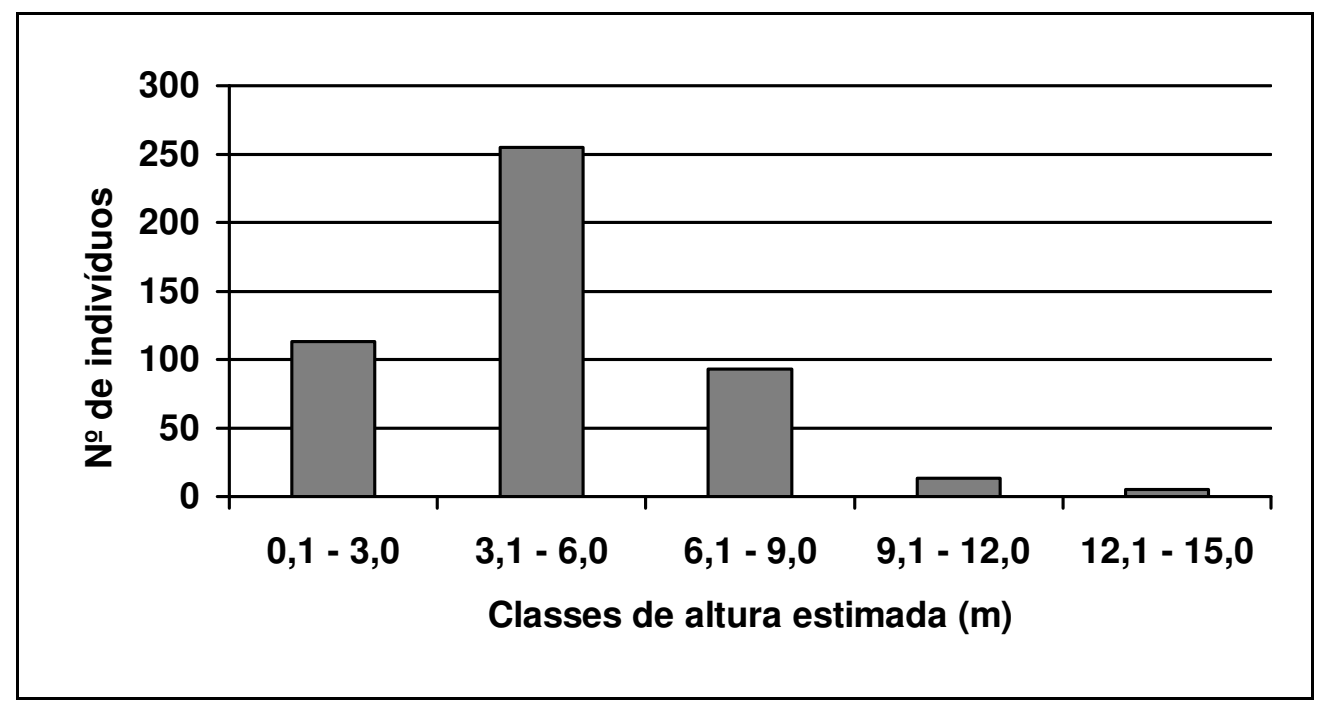

Figura 4 - Classes de altura estimada dos indivíduos encontrados na arborização das vias públicas dos bairros Vila Raycos, Jardim Independência, Jardim Califórnia e na parte antiga da Vila Santos Dumont da cidade de Franca, SP.

Em relação à poda, 71\% apresentaram algum tipo de poda e $29 \%$ não foram podadas. Quanto ao tipo de poda, 55,6\% sofreram poda moderada e 44,4\% poda drástica. Estas podas foram realizadas de forma emergencial e foram necessárias, na maioria das vezes, porque de algum modo os indivíduos estavam atrapalhando a passagem dos pedestres, a sinalização de trânsito ou a fiação. Por isso constatou-se que apenas 9,4\% obstruíam a passagem de pedestres, somente 3,3\% impediam a visualização da sinalização de trânsito e 12\% conflitavam com a fiação. Estes baixos índices foram constatados em decorrência das podas, porque se estas não tivessem sido realizadas a porcentagem de indivíduos que interfeririam nesses fatores seria maior.

Qualquer poda pode representar risco de entrada de pragas e doenças, devendo ser evitada. $O$ que se percebe é que as podas freqüentemente são realizadas pelos próprios moradores e sem critério algum, ofendendo a fisionomia natural da planta para forjar um aspecto estético desejado ou para evitar que a planta atrapalhe em algum fator. Além disso, 
as companhias de energia elétrica efetuam a poda de todas as árvores em conflito com a fiação em determinadas épocas, sem respeitar o estado fenológico em que se encontram algumas espécies. Estas práticas nos levam a encontrar árvores com galhos mutilados, causando um grave desequilíbrio entre a parte aérea e radicular da planta (SOARES, 1998), o que pode levar até mesmo à queda da árvore. Note-se ainda que "as árvores não podadas [...] são mais belas, mais saudáveis e mais longevas" (SOARES, 1998). O emprego de espécies mais adequadas a cada local evitaria grande parte destas podas.

A média do número de indivíduos a cada dez metros lineares de vias públicas foi de 0,364, sendo pouco superior aos valores encontrados nos bairros Rancho Novo e Centro da cidade de Nova Iguaçu, RJ, que foram de 0,358 e 0,269, respectivamente (ROCHA; LELES; OLIVEIRA NETO, 2004). A média de árvores a cada dez metros de calçada encontrada na amostragem foi de 0,182 . Este resultado aponta uma deficiência na arborização, uma vez que é recomendada pelo menos uma árvore a cada dez metros de calçada para uma arborização adequada (MILANO; DALCIN, 2000). Em todas as ruas analisadas há a necessidade de implementar a arborização, pois nos bairros da amostragem nenhuma rua se enquadrou no parâmetro recomendado (Tabela 3). A área estudada apresentou-se bastante diversificada, porém com distribuição irregular, observando-se árvores em locais inviáveis e longos trechos viáveis desprovidos de arborização.

O planejamento da arborização torna-se imprescindível para que os benefícios que a mesma proporciona à população sejam atingidos. A cidade torna-se um ambiente mais humanizado, saudável e confortável através do seu planejamento. A implantação de parques e ruas arborizadas são providências que cabem também aos governantes e às grandes empresas, uma vez que aumenta o verde e as áreas de infiltração de águas pluviais (BRANCO, 2003).

A utilização de espécies inadequadas em locais não apropriados causa muitos transtornos e prejuízos (LORENZI, 2002). Calhas e bueiros entupidos, calçadas danificadas, conflito com a fiação e equipamentos da infra-estrutura urbana, quedas de galhos e gastos excessivos com podas poderiam ser evitados se fosse observada de modo mais objetivo e particular a compatibilidade da arborização no contexto urbano (CEMIG, 2001). Deve-se atentar às peculiaridades de cada cidade e, de modo mais específico, de cada bairro, utilizando as espécies mais adequadas às características de cada local. 
Tabela 3 - Distribuição dos indivíduos pelas vias públicas na arborização dos bairros Vila Raycos, Jardim Independência, Jardim Califórnia e na parte antiga da Vila Santos Dumont da cidade de Franca, SP.

\begin{tabular}{|c|c|c|c|c|}
\hline Nome da rua & $\begin{array}{l}\text { Indiv. } \\
\text { encon- } \\
\text { trados }\end{array}$ & $\begin{array}{l}\text { Comprimen- } \\
\text { to da rua } \\
\text { (m)* }\end{array}$ & $\begin{array}{l}\text { Qtde. de } \\
\text { árvores a cada } \\
10 \text { metros } \\
\text { lineares de via } \\
\text { pública }\end{array}$ & $\begin{array}{l}\text { Qtde. de } \\
\text { árvores a } \\
\text { cada } 10 \\
\text { metros de } \\
\text { calçada** }^{\star *}\end{array}$ \\
\hline Salvador Mazini & 9 & 64,6 & 1,393 & 0,696 \\
\hline Teodoro M. Tristão & 12 & 104 & 1,153 & 0,576 \\
\hline Da Imprensa & 18 & 239,4 & 0,751 & 0,375 \\
\hline Doutor João Deocleciano Luz & 44 & 748 & 0,588 & 0,294 \\
\hline Corifeu de Azevedo Marques & 40 & 800 & 0,500 & 0,250 \\
\hline César Ribeiro & 33 & 670,8 & 0,491 & 0,245 \\
\hline Oscar Louzada & 14 & 319 & 0,438 & 0,219 \\
\hline Alcides Tozzi & 8 & 197 & 0,406 & 0,203 \\
\hline Antônio Ribeiro Novo & 18 & 444 & 0,405 & 0,202 \\
\hline Francisco Társia & 38 & 960 & 0,395 & 0,197 \\
\hline Major A. Urias do Nascimento & 31 & 785 & 0,394 & 0,197 \\
\hline Pedro Guilherme Voz & 6 & 156 & 0,384 & 0,192 \\
\hline Liberdade & 28 & 755 & 0,370 & 0,185 \\
\hline Alberto de Azevedo & 29 & 809 & 0,358 & 0,179 \\
\hline Doutor Antônio Petráglia & 10 & 315,1 & 0,317 & 0,158 \\
\hline Cavalheiro Petráglia & 32 & 1.040 & 0,307 & 0,153 \\
\hline Vicente Raimundini & 11 & 376 & 0,292 & 0,146 \\
\hline Estevam Marcolino & 29 & 1.125 & 0,257 & 0,128 \\
\hline Américo Caravieri V. Pucci & 19 & 754,2 & 0,251 & 0,125 \\
\hline Doutor Carrão & 21 & 890,9 & 0,235 & 0,117 \\
\hline Francisco Marcolino & 8 & 366 & 0,218 & 0,109 \\
\hline Padre Conrado & 9 & 646 & 0,138 & 0,069 \\
\hline Simpliciano Pombo & 11 & $1.023,8$ & 0,107 & 0,053 \\
\hline Odoni Mazini & 1 & 206 & 0,048 & 0,024 \\
\hline Travessa Augusta & 0 & 124 & 0 & 0 \\
\hline Travessa Israel J. Oliveira & 0 & 107 & 0 & 0 \\
\hline Ana Nicácio & 0 & 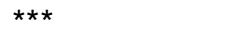 & 0 & 0 \\
\hline Vila Maria Afonso & 0 & $\star \star \star *$ & 0 & 0 \\
\hline
\end{tabular}

Das espécies encontradas na amostragem, Anadenanthera macrocarpa, Caesalpinia pluviosa, Ceiba speciosa, Ficus benjamina, Mangifera indica, Myroxylon peruiferum, Nerium oleander, Pachira aquatica, Persea americana, Schizolobium parahyba, Spathodea nilotica, Syzygium cumini, Tamarindus indica e Terminalia catappa, não são indicadas para o plantio nas calçadas, pois não se enquadram nos critérios de escolha de espécies recomendados, tais como: porte adequado ao espaço disponível, tronco o mais retilíneo possível, sem espinhos e sem ramificações até no mínimo dois metros; sistema radicular profundo, sem raízes superficiais muito espessas; apresentar rusticidade e resistência a pragas, estando adaptada ao clima do local destinado, justificando o uso das espécies nativas; não 
apresentar princípios tóxicos ou alérgicos; possuir folhagem persistente e copa densa em climas quentes; em climas frios, espécies caducifólias proporcionam maior aproveitamento do calor solar no inverno; evitar espécies que provocam problema de detritos (folhas decíduas e grandes ou folíolos miúdos que entopem ralos, calhas e bueiros; flores e frutos grandes); e produzir frutos pequenos e silvestres (DEMATTÊ, 1997; CEMIG, 2001; COELBA, 2002).

Para que haja um estímulo no plantio de mais árvores e uma redução nos problemas decorrentes do mesmo, indica-se a utilização de postes mais altos (SOARES, 1998), propõe-se fiação subterrânea (DEMATTÊ, 1997), fiação compacta ou cabos encapados (MILANO; DALCIN, 2000), e sugere-se incentivos fiscais aos imóveis que possuam arborização, como desconto no IPTU (SANTOS, 2001).

\section{CONCLUSÃO}

O baixo índice de distribuição dos indivíduos pelas vias públicas mostrou a necessidade de implementar a arborização da área, ressaltando a importância de um melhor planejamento urbanístico.

A maioria dos indivíduos encontrados foi de espécies exóticas, sendo poucos nativos da flora regional, contrariando a legislação municipal.

A incompatibilidade de espécies com a infra-estrutura urbana foi a principal causa de conflito com a mesma, fazendo com que a maioria dos indivíduos apresentassem podas, que seriam desnecessárias se houvesse a observância de alguns critérios na escolha das espécies.

\section{REFERÊNCIAS}

ALMEIDA, L. M. A.; RIGOLIN, T. B. Geografia. São Paulo: Ática, 2002. 464p. (Série Novo Ensino Médio).

BRANCO, S. M. Ecologia da cidade. 2. ed. São Paulo: Moderna, 2003. 64p. (Coleção Desafios).

COMITÊ DA BACIA HIDROGRÁFICA DO SAPUCAÍ MIRIM/GRANDE. 2o Relatório de Situação dos Recursos Hídricos da Bacia Hidrográfica do Sapucaí-Mirim/Grande. Franca: [s.n.] set. 2005. 1CD-ROM. 
CEMIG. Companhia Energética de Minas Gerais. Manual de Arborização. Belo Horizonte, 2001. 40p.

COELBA. Companhia de Eletricidade do Estado da Bahia. Guia de Arborização Urbana. Salvador: Venture, 2002. 55p.

DEMATTÊ, M. E. S. P. Princípios de paisagismo. Jaboticabal: Funep, 1997. 104p.

EMBRAPA. Centro Nacional de Pesquisa de Monitoramento por Satélite. Brasil visto do espaço. Disponível em: <http://www.cdbrasil.cnpm.embrapa.br/sp>. Acesso em: 29 ago. 2006.

FRANCA. Código do meio ambiente do município de Franca. Lei Complementar nº 09/96 de 26/11/1996. Publicação da Secretaria Municipal do Meio Ambiente e de Projetos Especiais de Franca - Prefeitura Municipal de Franca, 1996. 24p.

GREY, G. M.; DENEKE, F. J. Urban Forestry. New York: John Wizey, 1978. 280p.

IBGE. Instituto Brasileiro de Geografia e Estatística. Censo 2000. Disponível em: <http://www.ibge.gov.br/cidadesat/default.php>. Acesso em: 17 ago. 2006.

LORENZI, H. Árvores Brasileiras: manual de identificação e cultivo de plantas arbóreas nativas do Brasil. 4. ed. Nova Odessa: Plantarum, 2002. 368p. v. 1.

MARQUETTI, E. H. Franca: Geografia e História do município. 2. ed. Franca: [s.n.], 1992. $101 p$.

MASCARÓ, L; MASCARÓ, J. Vegetação urbana. 2.ed. Porto Alegre: Mais Quatro Editora, 2005. 204 p.

MILANO, M.S.; DALCIN, E. Arborização de vias públicas. Rio de Janeiro: Light, 2000. 206p.

MOREIRA, J. C.; SENE, E. Geografia para o Ensino Médio: Geografia Geral e do Brasil. São Paulo: Scipione, 2002. 528p. (Série Parâmetros). 
PREFEITURA MUNICIPAL DE FRANCA. Dados sobre Franca. Disponível em <http://www.franca.sp.gov.br/>. Acesso em: 20 jul. 2006.

ROCHA, R. T.; LELES, P. S. S.; OLIVEIRA NETO, S. N. Arborização de vias públicas em Nova Iguaçu: o caso dos bairros Rancho Novo e Centro. Revista Árvore. Universidade Federal de Viçosa, Viçosa, v. 28, n. 4, p. 599-607, 2004.

SANTOS, A. S. R. Arborização urbana: importância e aspectos jurídicos. Revista Meio Ambiente Industrial, São Paulo, v. 34, n. 33, nov./dez. 2001.

SILVA, V. A. Geografia do Brasil e Geral: Povos e Territórios. São Paulo: Escala Educacional, 2005. 400p.

SOARES, M. P. Verdes urbanos e rurais: orientação para arborização de cidades e sítios campesinos. Porto Alegre: Cinco Continentes, 1998. 242p.

TEIXEIRA, I. F. Análise qualitativa da arborização de ruas do conjunto habitacional Tancredo Neves, Santa Maria - RS. Ciência Florestal. Universidade Federal de Santa Maria, Santa Maria, v. 9, n. 2, p. 9-21, 1999.

TELELISTAS.NET. Mapas \& Rotas. Disponível em: <http://www.riolistas.com.br/ templates/mapas_rotas_exibe.aspx?zoom=8000>. Acesso em: 29 ago. 2006.

VIEIRA, N. M. Geografia de Franca: Aspectos físicos. Franca: Comércio da Franca, 1971. 96p. 